\title{
Self-healing High Strength and Thermal Conductivity of 3D Graphene/PDMS Composite by Optimization of Multiple Molecular Interactions
}

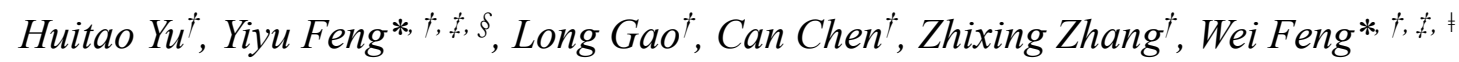

$\uparrow$ School of Materials Science and Engineering, Tianjin University, Tianjin 300072, P. R. China.

\$ Key Laboratory of Advanced Ceramics and Machining Technology, Ministry of Education, Tianjin 300072, P. R. China;

$\S$ Key Laboratory of Materials Processing and Mold, Ministry of Education, Zhengzhou University, Zhengzhou, 450002, China

₹ Collaborative Innovation Center of Chemical Science and Engineering, Tianjin 300072, P. R. China;

\section{Corresponding author:}

*Yiyu Feng; e-mail fengyiyu @tju.edu.cn.

*Wei Feng; e-mail weifeng@tju.edu.cn.

\section{Experimental Section}

\section{Materials}

Graphene oxide (GO) was prepared by an improved Hummers method. ${ }^{\mathbf{S 1}}$ The number and size of 
GO is controlled by the degree of oxidation reaction. The graphene aerogel (GA) was prepared by hydrothermal method with the density of $20-25 \mathrm{mg} / \mathrm{cm}^{3} . \mathbf{S 2}$ The preparation of PDMS-BE is based on the experimental process of Lai. ${ }^{\mathbf{S 3}}$

\section{Supporting Figures and Table}

(a)<smiles>Cc1cc(=O)nc(NC(=O)NCCC(C)(C)C)[nH]1</smiles>

(b)<smiles>[R18]c1ccc(B(O)c2ccc(C(=O)Cl)cc2)cc1</smiles>

(d)

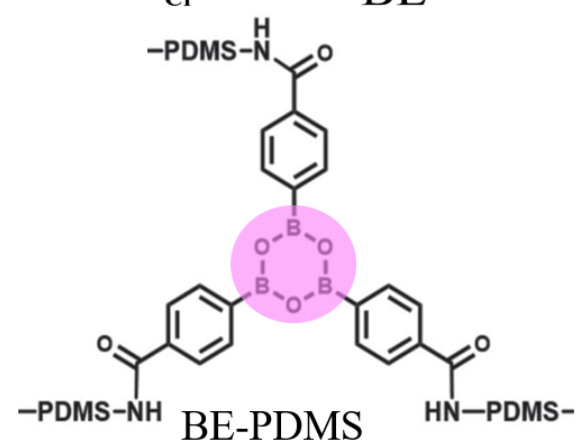

(c)
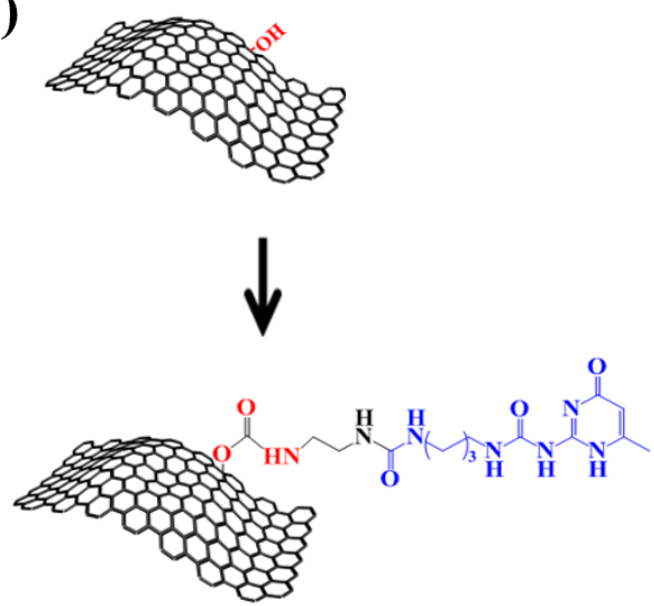

GA-UPy

Figure S1 Illustration for preparation processes of (a) UPy, (b) BE and (c) Graphene Aerogel-UPy. (d) The structure of PDMS-BE. 


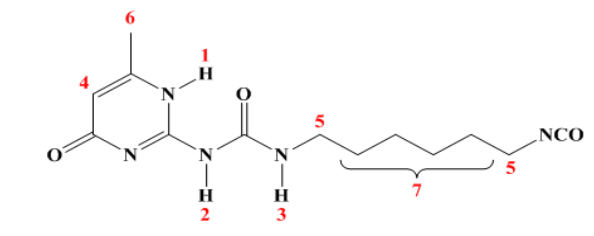

6

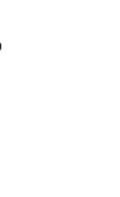
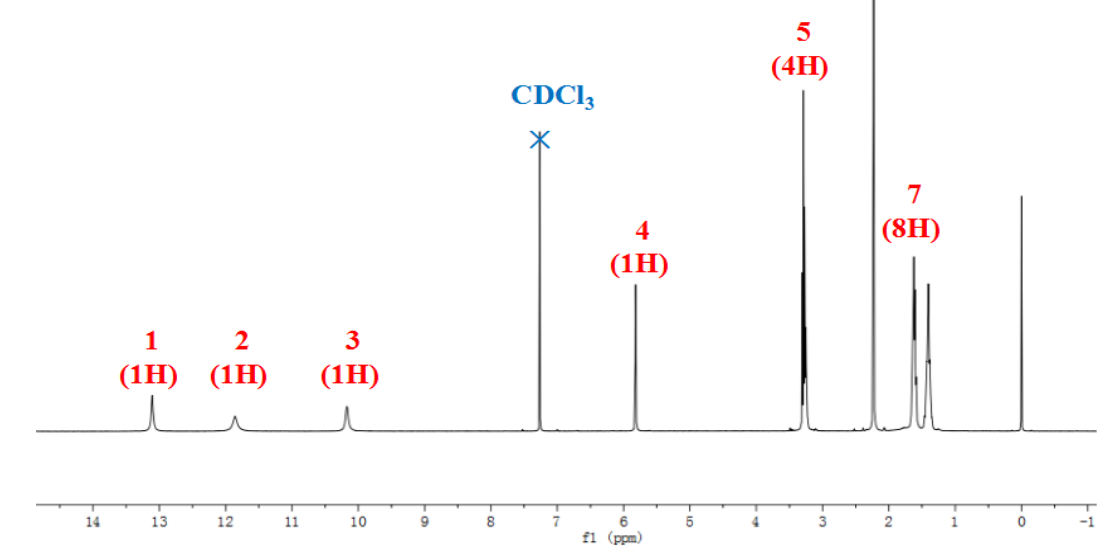

Figure S2. ${ }^{1} \mathrm{H}$ NMR spectra of 2-ureido-4[1H]-pyrimidinone in $\mathrm{CDCl}_{3}$.

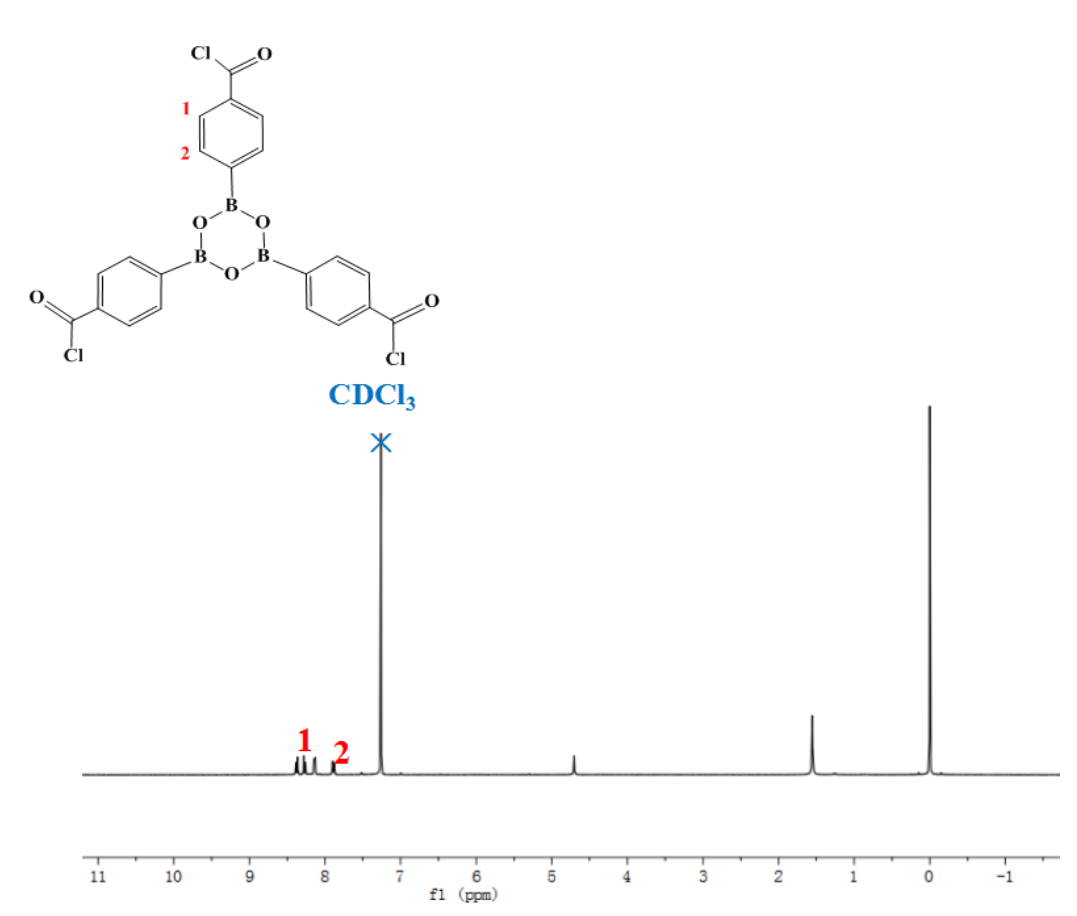

Figure S3. ${ }^{1} \mathrm{H}$ NMR spectra of $\mathrm{BE}$ in $\mathrm{CDCl}_{3}$. 


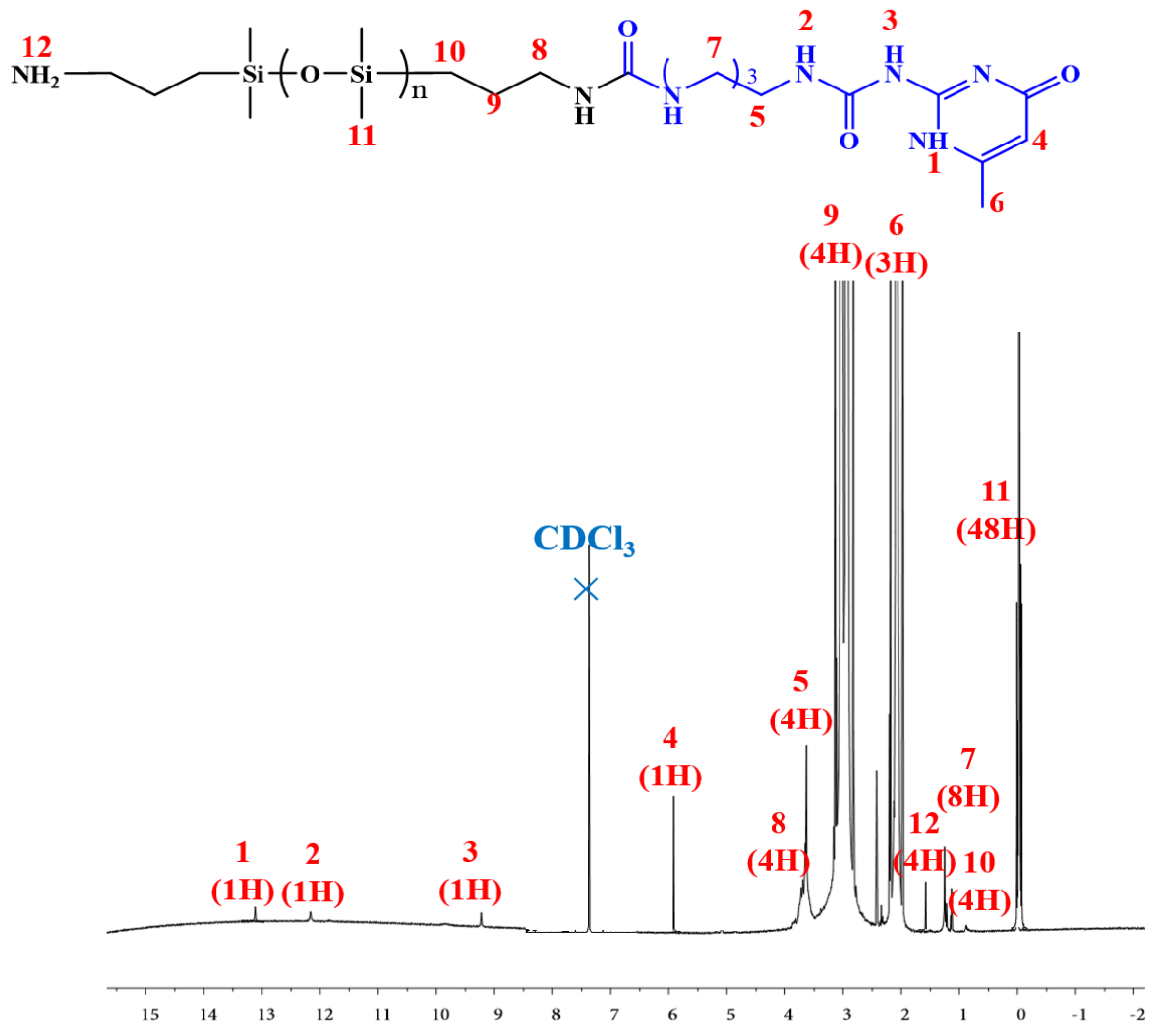

Figure S4. ${ }^{1} \mathrm{H}$ NMR spectra of NMR of $\mathrm{H}_{2} \mathrm{~N}-\mathrm{PDMS}-\mathrm{UPy}$ in $\mathrm{CDCl}_{3}$.<smiles>C[Si](C)(I)O[Si](C)(C)CCCN</smiles>

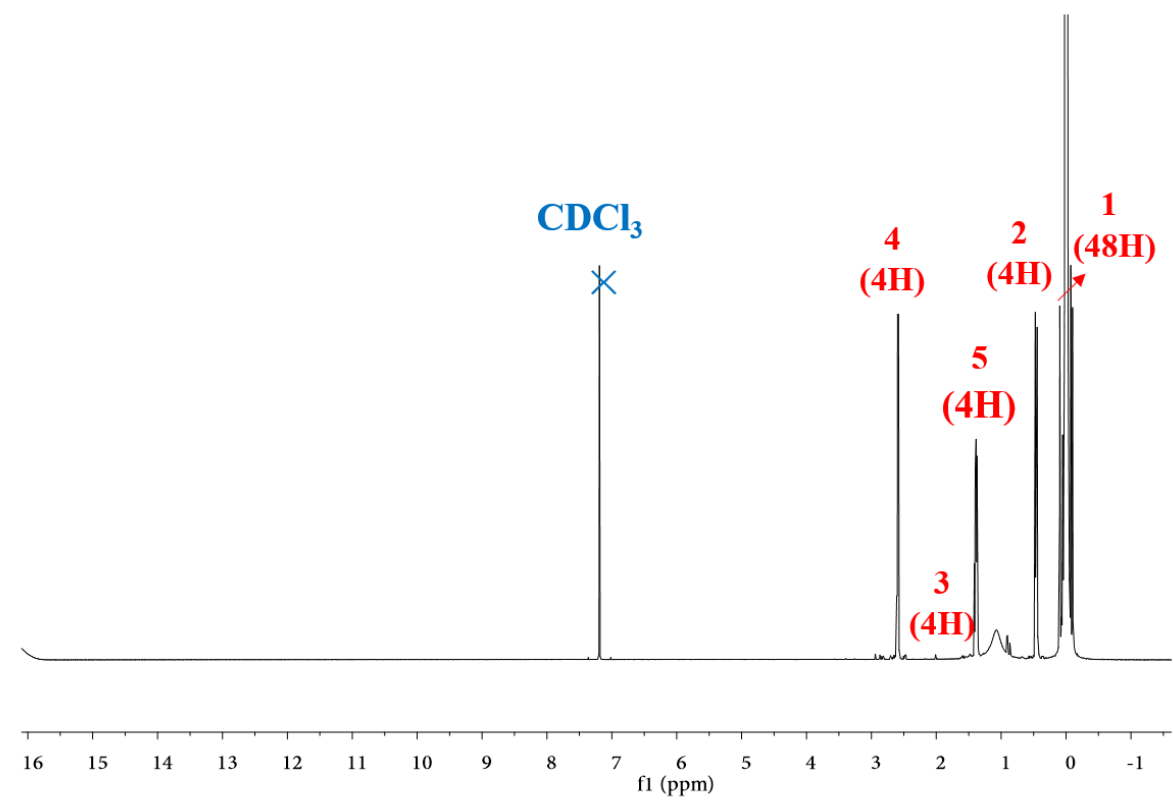

Figure S5. ${ }^{1} \mathrm{H}$ NMR spectra of NMR of PDMS in $\mathrm{CDCl}_{3}$.

${ }^{1} \mathrm{H}$ NMR (400 MHz, $\left.\mathrm{CDCl}_{3}, 298 \mathrm{~K}, \delta_{\mathrm{ppm}}\right): 3.77$ (q, 8H, $\left.\mathrm{CH}_{2}, 2\right), 3.02$ (m, 4H, $\left.\mathrm{CH}_{2}, 3\right), 0.05$ (m, 48H, 
$\left.\mathrm{CH}_{3}-\mathrm{Si}, 1\right), 0.87$ (m, 4H, $\left.\mathrm{CH}_{2}-\mathrm{Si}, 2\right), 3.02$ (m, 4H, $\left.\mathrm{CH}_{2}, 3\right), 3.77$ (q, 8H, $\left.\mathrm{CH}_{2}, 4\right), 1.23$ (m, 4H, NH , 5), ppm.

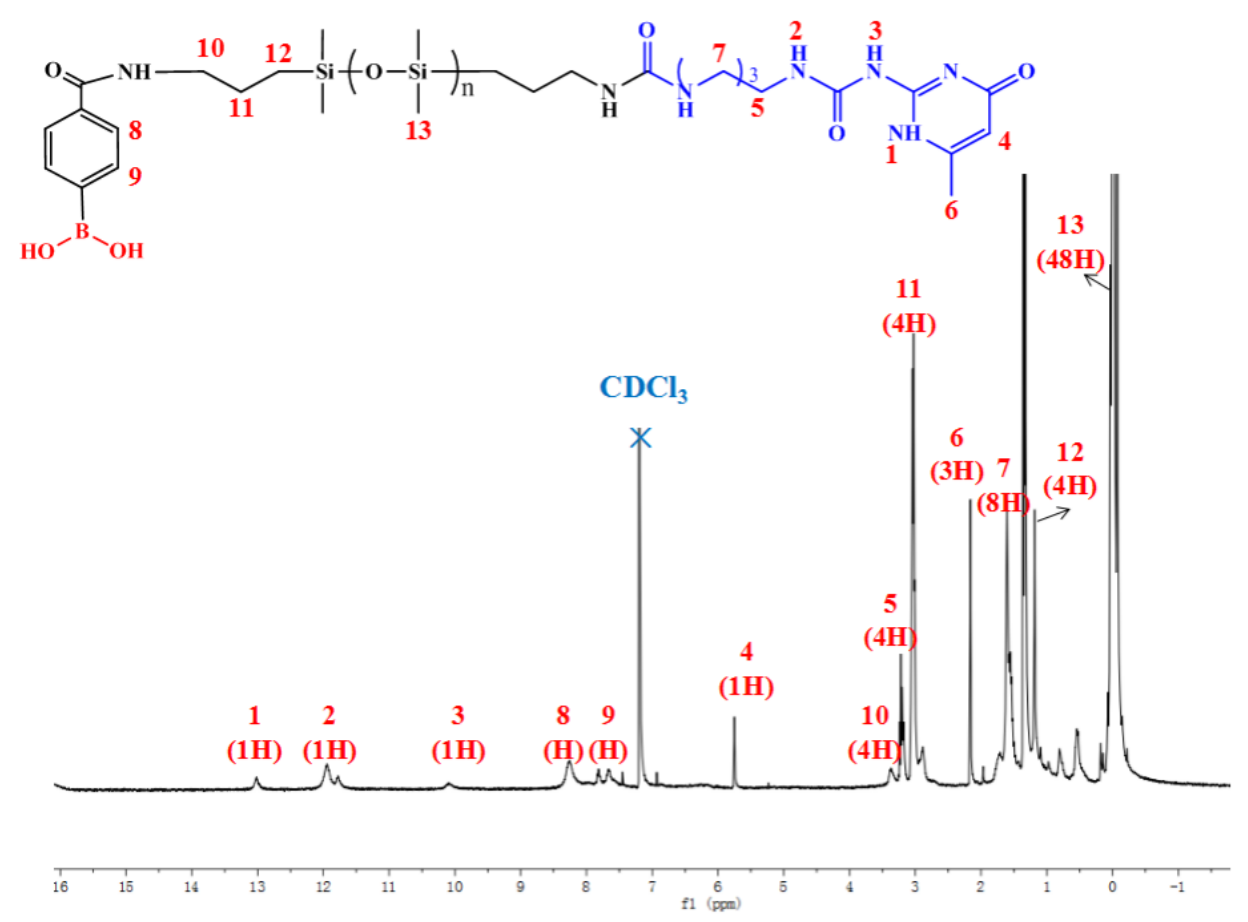

Figure S6. ${ }^{1} \mathrm{H}$ NMR spectra of NMR of $\mathrm{H}_{2} \mathrm{~N}-\mathrm{PDMS}-\mathrm{UPy}$ PDMS and BE-PDMS $1: 3-\mathrm{UPy}$ in $\mathrm{CDCl}_{3}$. 

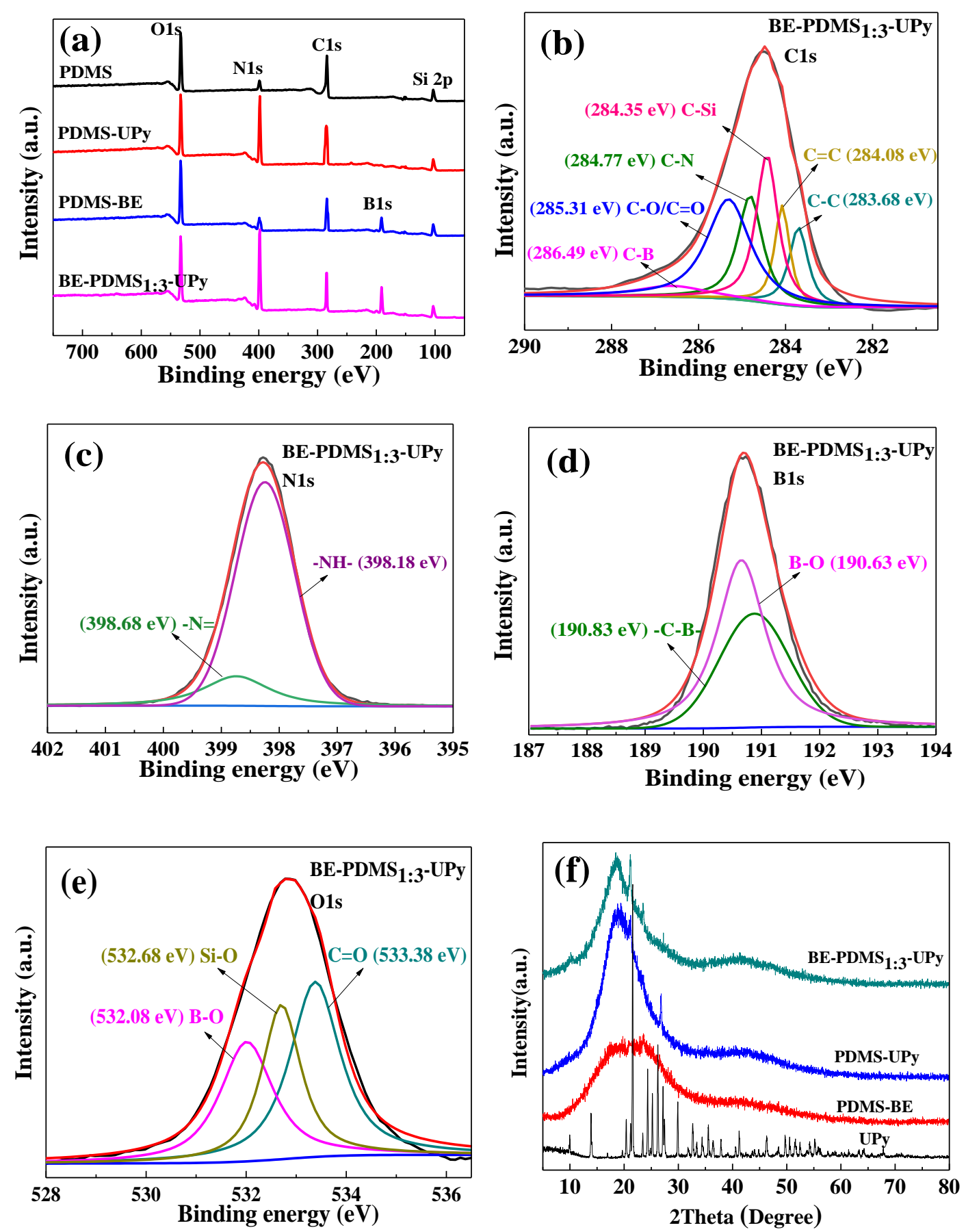

Figure S7. Structural characterization of polymers. (a) XPS spectrum of PDMS, UPy, PDMS-UPy and BE-PDMS 1:3-UPy. Magnification of (b) C1s, (c) N1s and (d) B1s (e) O1s of BE-PDMS $1: 3-U P y$. (f) The XRD spectrum of UPy, PDMS-BE, BE-PDMS $1: 3-$ UPy and PDMS-UPy.

These samples were investigated to determine the synergistic effects of $\mathrm{H}-$ bonds and B-O bonds on the self-healability and mechanical strength. 

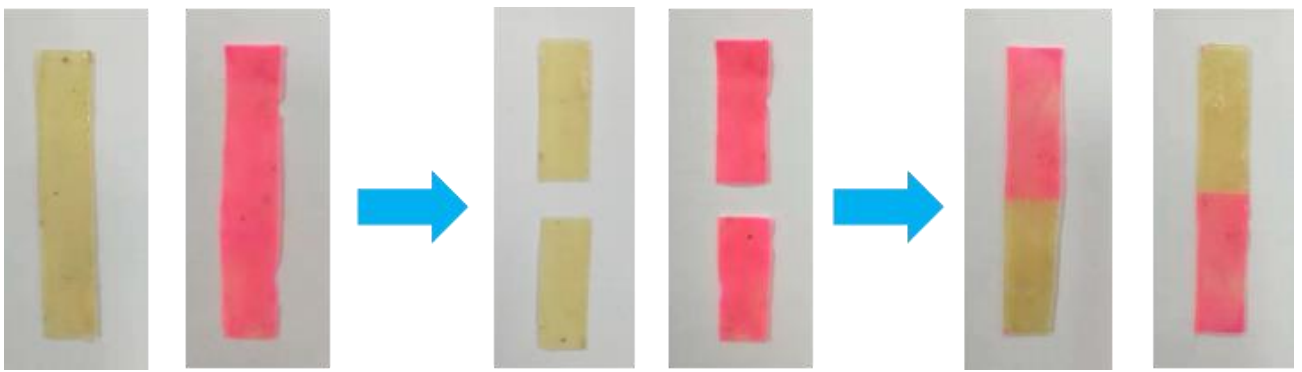

Figure S8. Self-healing physical photograph. The picture shows the self-healing physical map, and the red color is stained with Rhodamine B. 

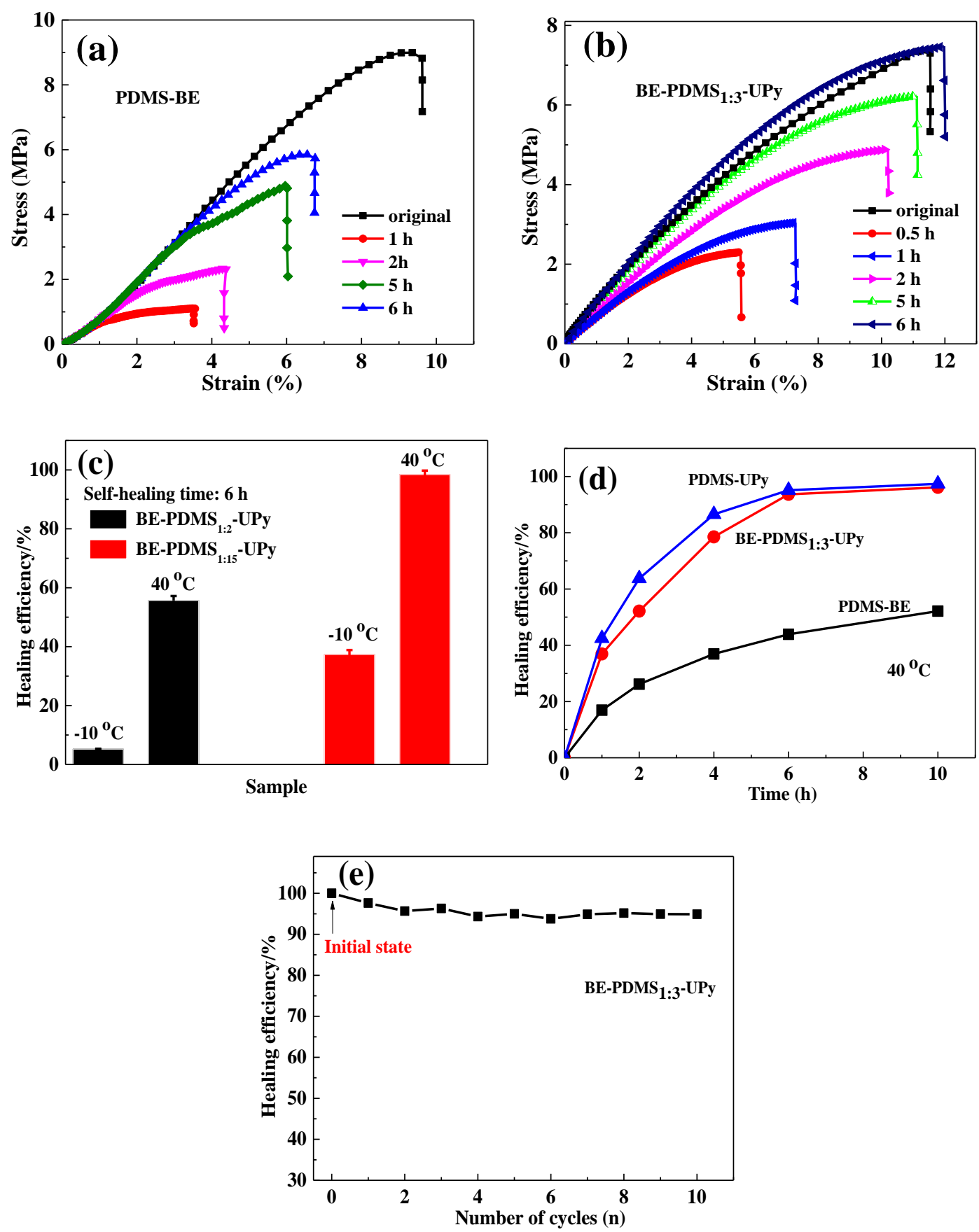

Figure S9. Strength and self-healing properties of polymer materials (a) Self-healing efficiency of PDMS-UPy and PDMS-BE at $40{ }^{\circ} \mathrm{C}$. (b) Stress-strain behavior of healed BE-PDMS $1: 3-\mathrm{UPy}$ at $40{ }^{\circ} \mathrm{C}$ for different healing times. (c) Self-healing efficiency of BE-PDMS $1: 15$-UPy and BE-PDMS $1: 2$-UPy at $40{ }^{\circ} \mathrm{C}$ and $-10{ }^{\circ} \mathrm{C}$ for $6 \mathrm{~h}$, respectively. (d) Stress-strain curves of the original and healed polymers of PDMS-BE. (e) Self-healing efficiency of BE-PDMS $1: 3-U P y$ under 10 times self-healing at $40{ }^{\circ} \mathrm{C}$ for 6 h. 

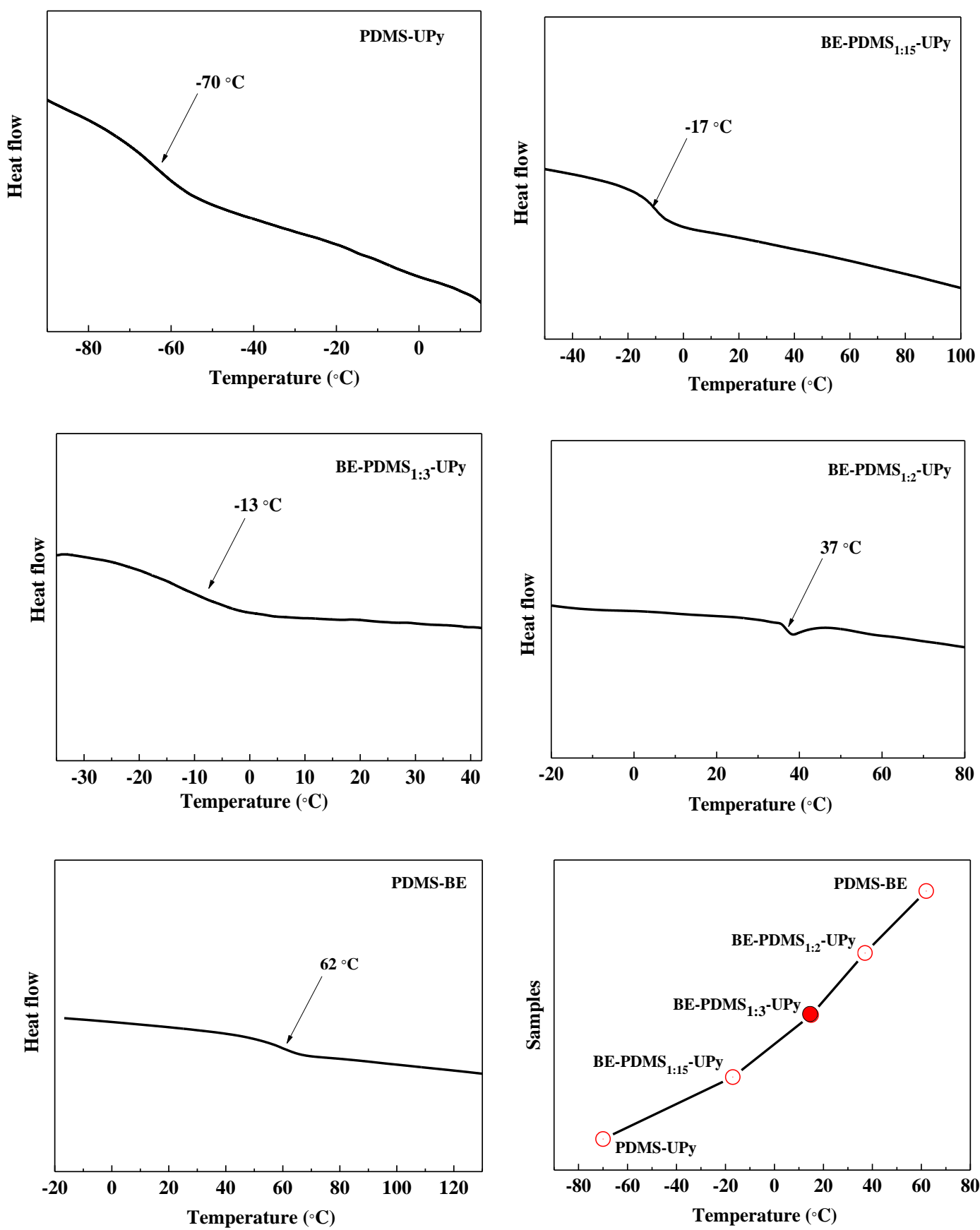

Figure S10. Glass transition temperature $\left(T_{\mathrm{g}}\right)$ of polymers with different $\mathrm{MR}_{\mathrm{U}: \mathrm{BE}}$. 

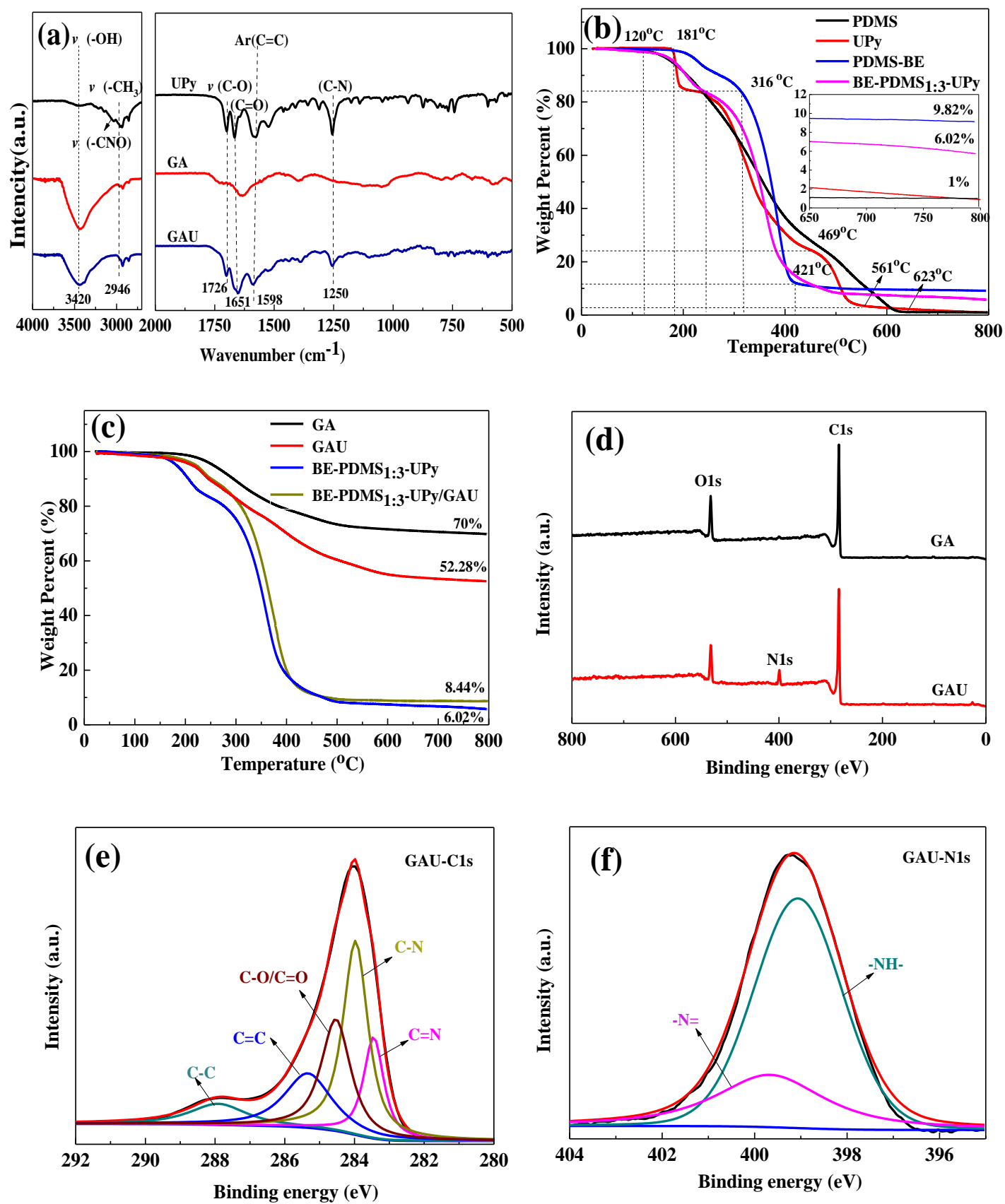

Figure S11. The structural characterization of graphene materials and the graphene-based polymer composites. (a) FT-IR survey of GA, UPy and GAU. (b) TGA of PDMS, UPy, PDMS-BE and BE-

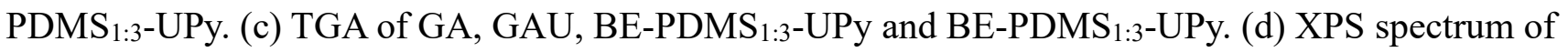
GA and GAU. XPS spectra (e) C1s and (f) N1s of GAU.

The chemical structure of GAU was investigated by FT-IR spectroscopy, TGA, and XPS. As shown in Figure S11a, GAU displays two new peaks at 1250 and $1650 \mathrm{~cm}^{-1}$ corresponding to the C-N 
stretching vibration and $\mathrm{C}=\mathrm{O}$ peak in the amide carbonyl group, respectively, and the characteristic peak of UPy at $1250 \mathrm{~cm}^{-1}$ (C-N stretching vibration). This proved that UPy was covalently grafted on GAU via an amide reaction. The grafting degree was measured from the different thermal stabilities (TGA, Figure S11b, 11c) of graphene and UPy, and the change in the chemical state of the elements (C 1s and N 1s XPS profiles, Figure S11d-f). As calculated by Supplementary Equation 1 and 2 and Table S1, the degree of UPy-NCO on GAU is $0.639 \mathrm{mmol} / \mathrm{g}$. After modification, the GAU aerogel was filled with BE-PDMS $1: 3-\mathrm{UPy}$ via vacuum adsorption assisted by the solvent-replacement method.

Thermogravimetric calculations use the following formulas:

$$
\begin{aligned}
& \Delta(U P y)=\frac{W\left(B E-\text { PDMS }_{1: 3}-\text { UPy }\right)-W(P D M S-B E)}{W(U P y)-W(P D M S-B E)} \times 100 \% \\
& \Delta(B E)=1-\Delta(U P y)
\end{aligned}
$$

Where the $\Delta(\mathrm{UPy})$ was the graft ratio of UPy at both ends of PDMS, the $\Delta(\mathrm{BE})$ was the graft ratio of B-O at both ends of PDMS, the weight loss rates of W(BE-PDMS $1: 3-U P y), W(U P y)$ and W(PDMSBE) were BE-PDMS $1: 3-U P y$, UPy and PDMS-BE respectively. 

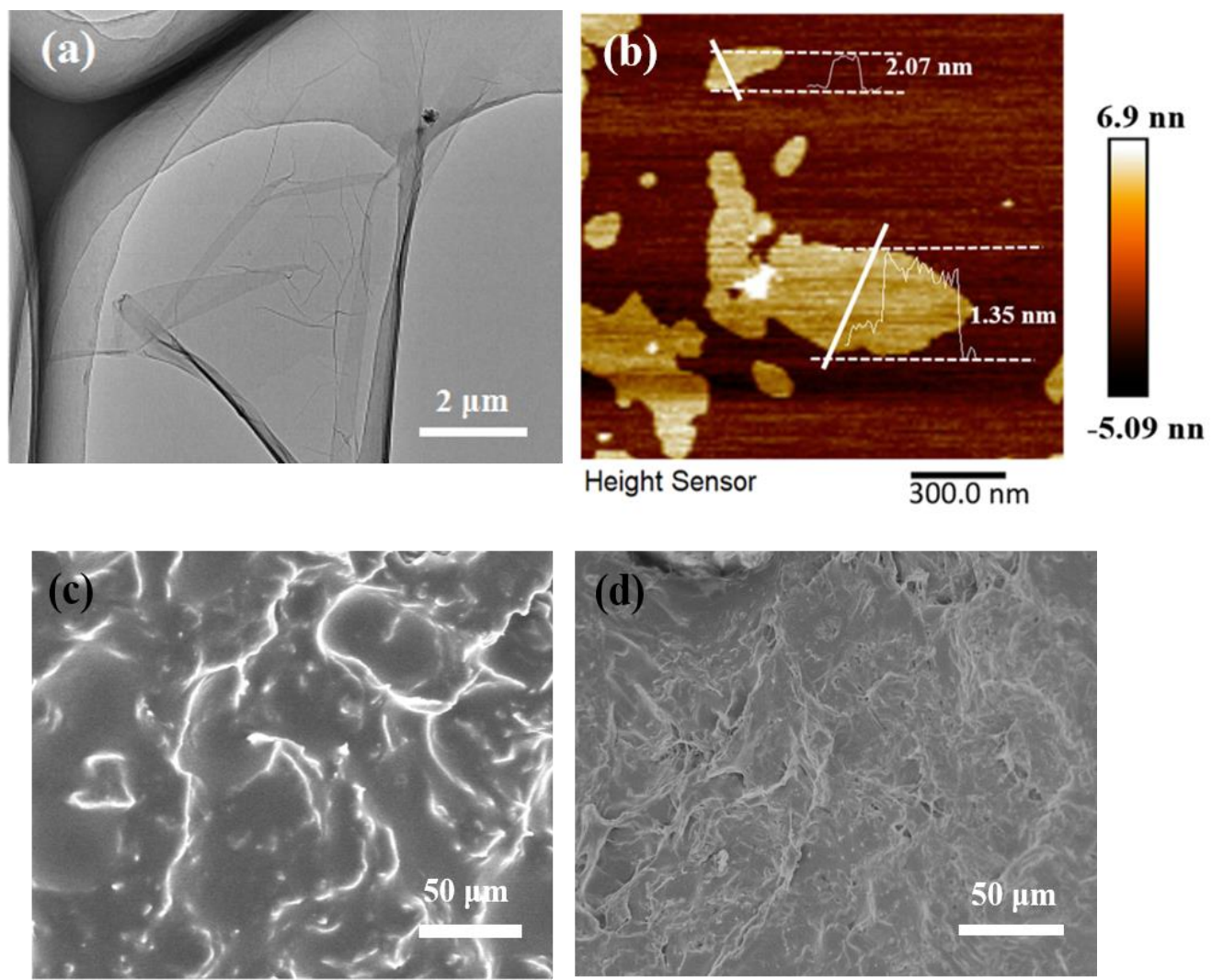

Figure S12. Morphology of materials. (a) TEM and (b) AFM image of graphene. SEM of (c)

$$
\text { GAU/BE-PDMS } 1: 3-U P y \text { and (d) GA/BE-PDMS } 1: 3-U P y
$$

As observed by TEM, the 3D porous graphene aerogel (GA) comprises hundreds of wrinkled singlelayer nanosheets (size: $60-100 \mu \mathrm{m}$, thickness: $1-5 \mathrm{~nm}$ ) with macropores of size $20-50 \mu \mathrm{m}$ (Figure S12a, b). The incorporation of polymers into a 3D template fills the macropores of the 3D network. The intermolecular H-bonds at the interface between GAU and BE-PDMS 1:3-UPy facilitate the uniform packing of polymers in the 3D network. A series of 3D uniform graphene-templated BEPDMS $_{1: 3-U P y}$ composites were obtained. The elasticity and robustness of the composites were controlled by changing the weight of BE-PDMS $1: 3-\mathrm{UPy}(50-95 \mathrm{wt} \%)$ in the composites. Finally, SEM was used to prove the composite uniformity. Compared with GA, the surface of polymer on GAU has better affinity and material density (Figure S12c, d). 

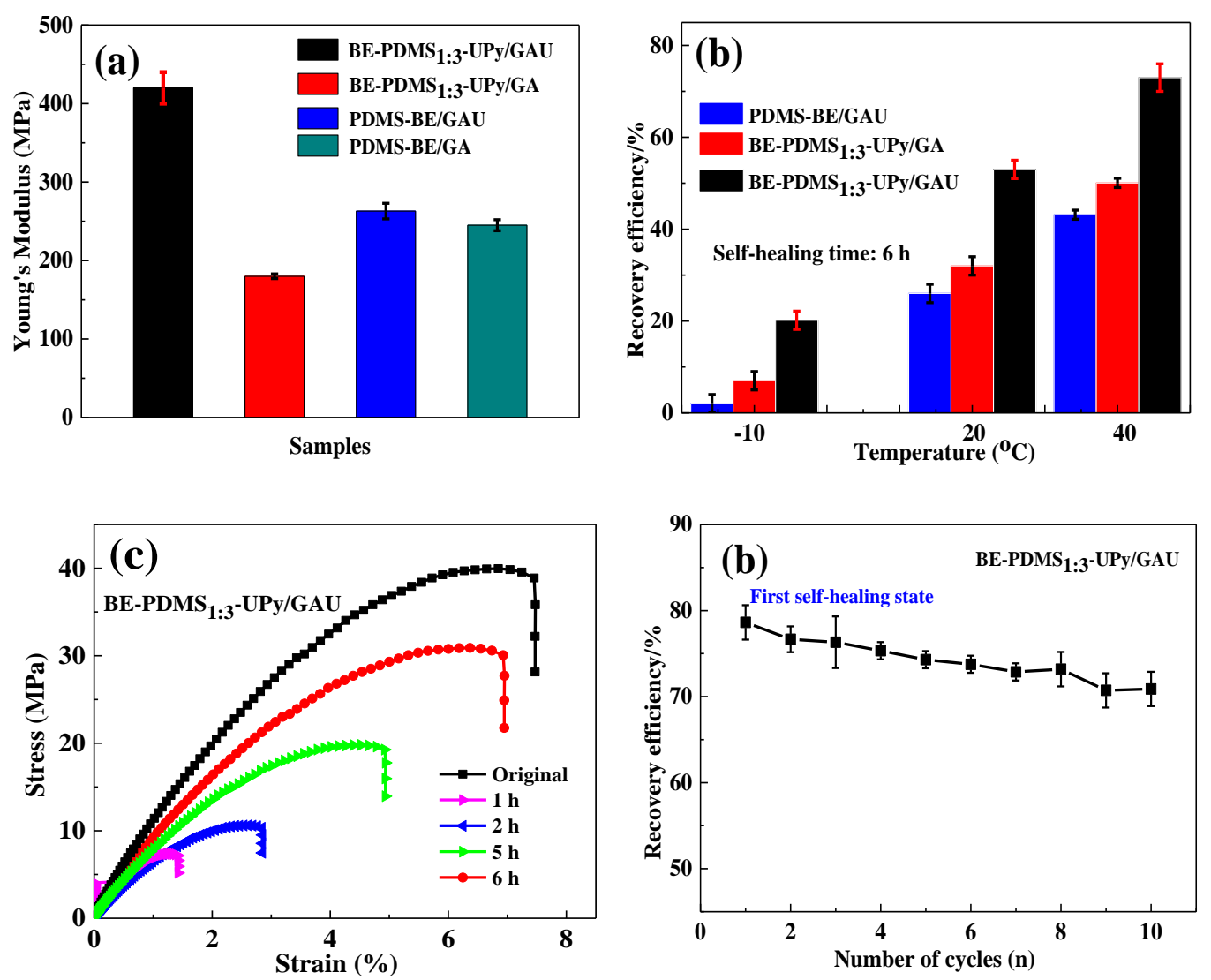

Figure S13. Mechanical and self-healing properties of composites. (a) The Young's modulus of BE-

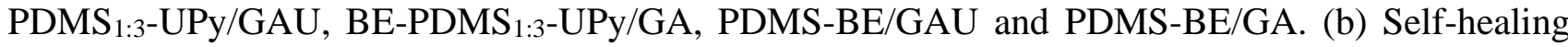
efficiency of BE-PDMS $1: 3-\mathrm{UPy} / \mathrm{GAU}, \mathrm{BE}^{-P D M S}{ }_{1: 3}-\mathrm{UPy} / \mathrm{GA}$ and PDMS-BE/GAU at $-10,20$ and $40{ }^{\circ} \mathrm{C}$. (c) Self-healing experiments for BE-PDMS $1: 3$-UPy/GAU sample under different healing times. (d) The self-healing efficiency cycles diagram of the material after 10 fracture healing. 

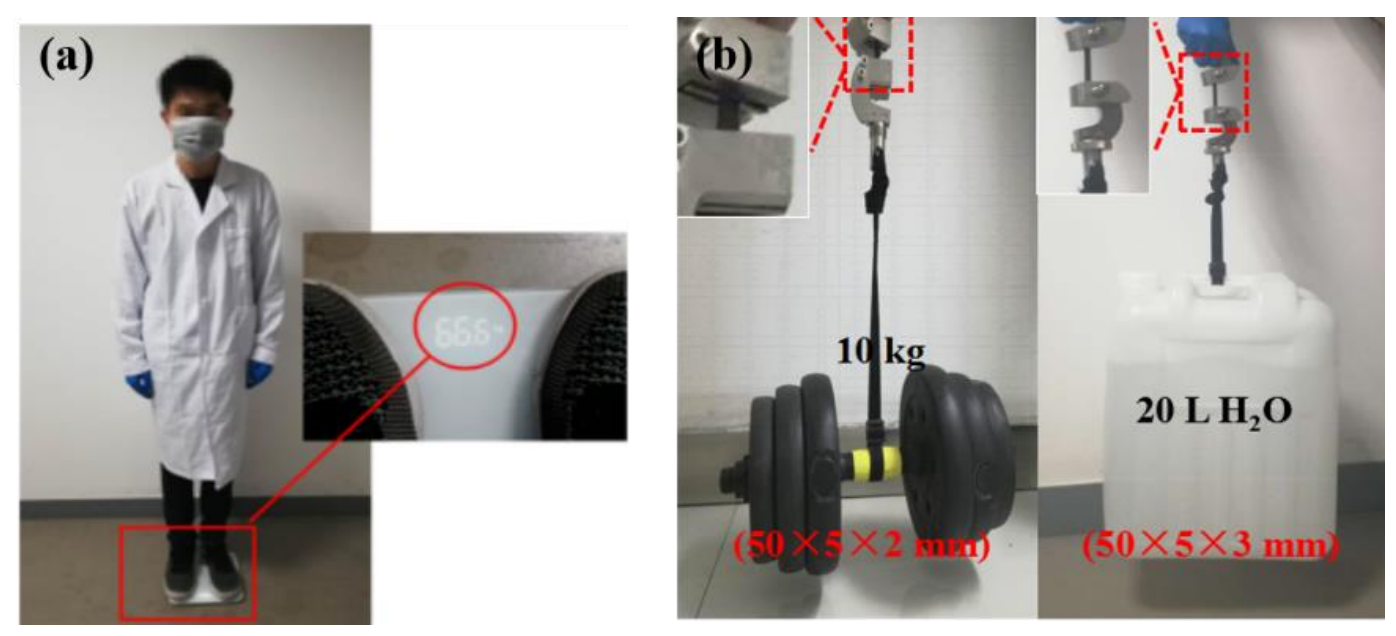

Figure S14. Practical application of mechanical properties. The weight of the body being tested (66.6 $\mathrm{kg})$. (b) The tensile strength of dumbbells $(50 \times 5 \times 2 \mathrm{~mm}, 10 \mathrm{~kg})$ and buckets $(50 \times 10 \times 3 \mathrm{~mm}, 20 \mathrm{~L})$ were tested after different sizes of self-healed materials.
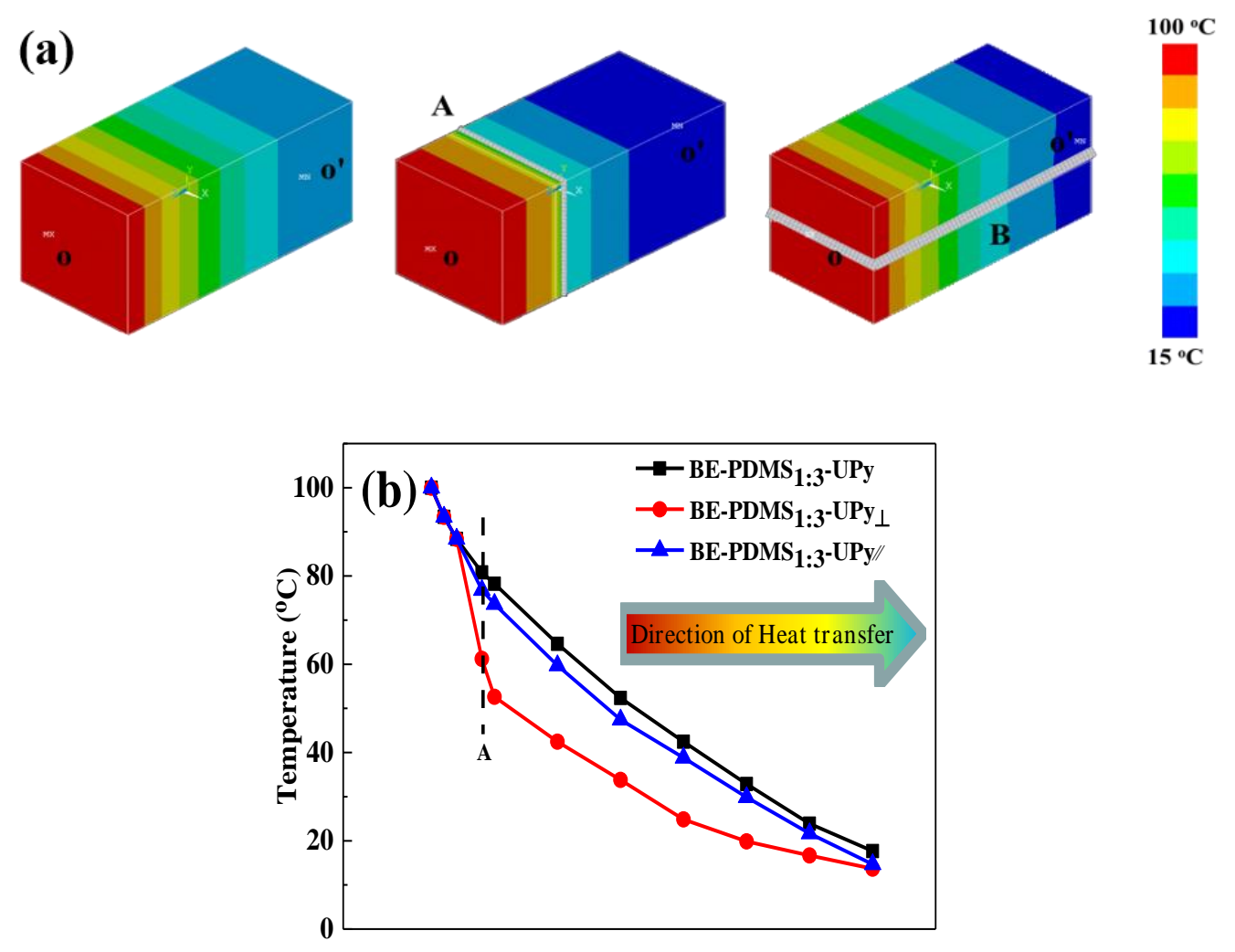

Figure S15. Thermal conduction simulation and thermal distribution under different damage models (table S8). (a) Finite element simulations of heat transfer in three models. (b) The relationship between the percentage of heat source distance and the temperature distribution of the three models. 


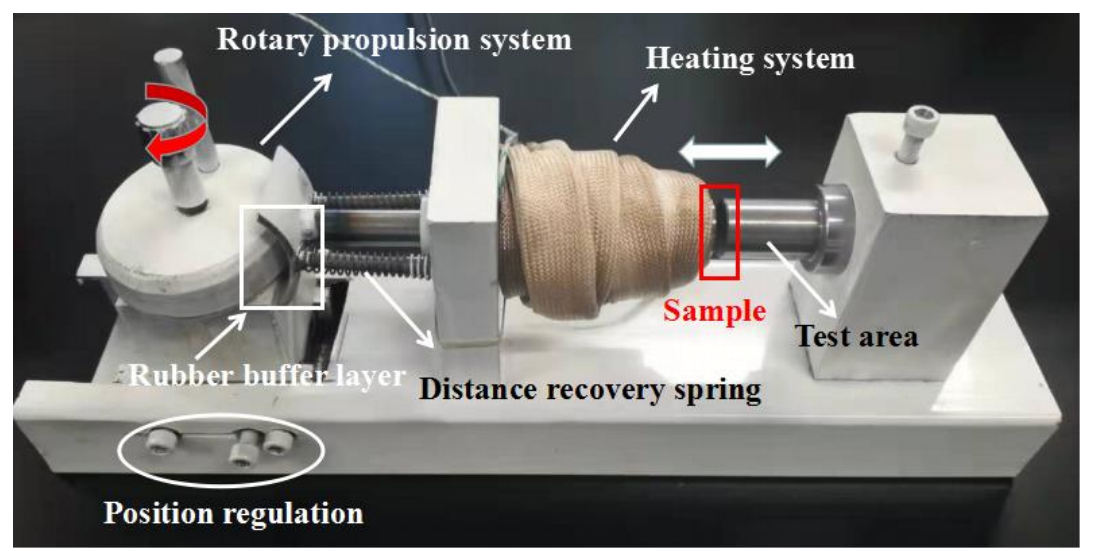

Figure S16. Self-made dynamic pressure heating equipment and structure analysis.

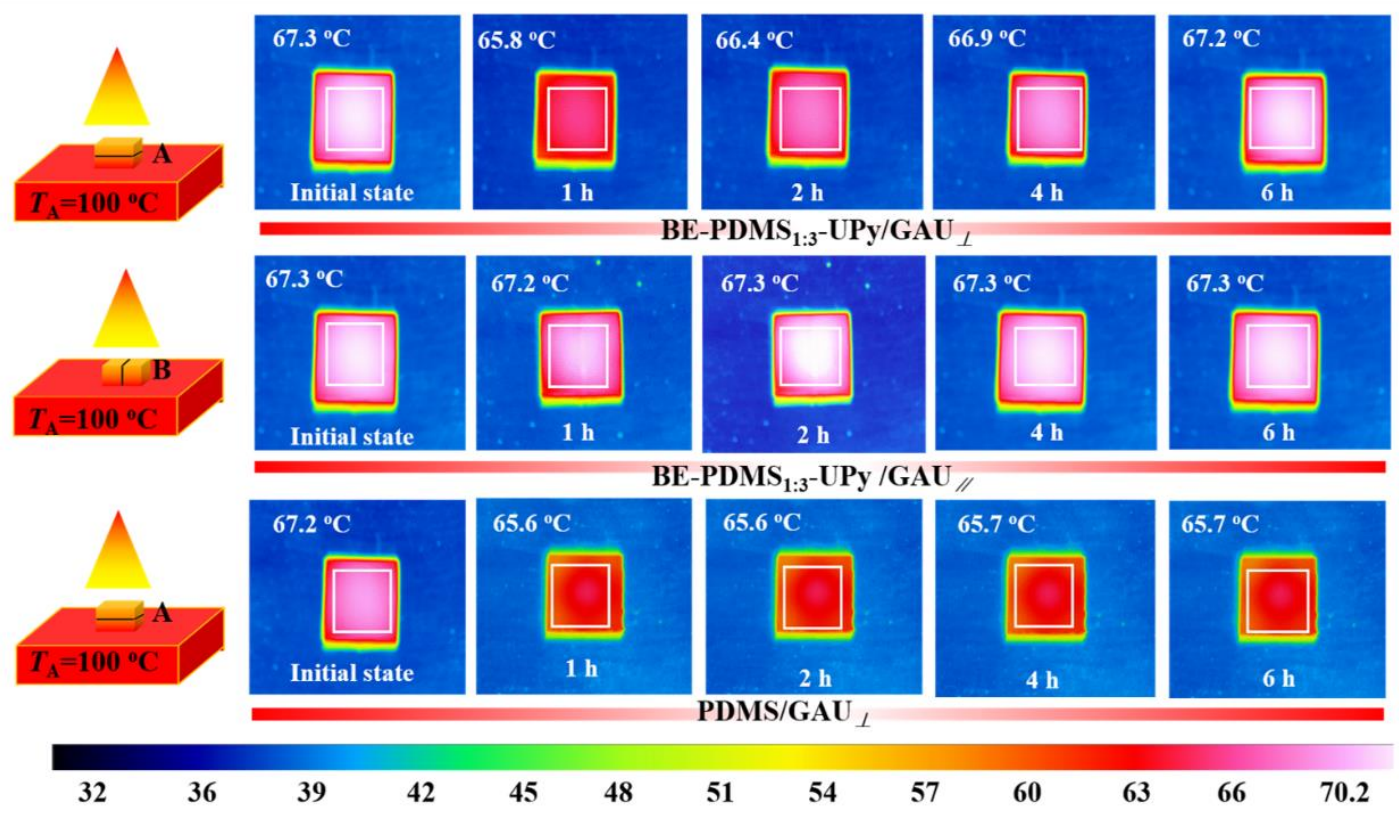

Figure S17. Thermal conductivity self-healing performance test. Thermal imaging cameras photos of different materials in three models at the same self-healing times $(1,2,4,6 \mathrm{~h})$.

We use self-healable robust BE-PDMS ${ }_{1: 3}$-UPy/GAU composite blocksb as a strong thermal conductor in dynamically pressurized and heat-output equipment to demonstrate heat conduction after self-healing. In Figure S17, it is found that the thermal conductivity of the BE-PDMS $1: 3-\mathrm{UPy} / \mathrm{GAU} \perp$ is significantly improved compared with the PDMS-GAU $\perp$ and BE-PDMS $1: 3-\mathrm{UPy} / \mathrm{GAU} / /$. With the 
prolonged self-healing time, the interface temperature is improved gradually. After self-healing at $40{ }^{\circ} \mathrm{C}$ for $6 \mathrm{~h}$, the temperature is basically restored to the heat conduction state of the complete structure. For materials that are parallel to the thermal interface material, the interface temperature is significantly higher than the vertical heat flow direction at the same self-healing time. This indicates that the BE-PDMS $1: 3-\mathrm{UPy} / \mathrm{GAU}$ polymer material has a good interface self-healing effect, and it can solve the problems that the weak internal damage interface of the graphene network and the high interface thermal resistance.

Table S1. Element contents of C, B, Si, N, O in PDMS, UPy, PDMS-BE, PDMS-UPy and BEPDMS $_{1: 3-U P y .}$

\begin{tabular}{|c|c|c|c|c|c|}
\hline Sample & C At.\% & B At.\% & Si At. \% & N At. $\%$ & O At. $\%$ \\
\hline PDMS & 63.29 & - & 9.25 & 10.15 & 17.22 \\
\hline UPy & 62.59 & - & - & 23.05 & 14.36 \\
\hline PDMS-BE & 55.83 & 8.47 & 7.19 & 6.22 & 13.29 \\
\hline PDMS-UPy & 62.63 & - & 5.76 & 16.39 & 15.22 \\
\hline BE-PDMS $_{1: 3}$-UPy & 59.27 & 4.61 & 6.31 & 12.89 & 16.92 \\
\hline BE-PDMS $_{1: 15}$-UPy & 57.32 & 3.27 & 5.26 & 18.07 & 16.08 \\
\hline BE-PDMS $_{1: 2-U P y}$ & 57.64 & 5.26 & 5.82 & 17.36 & 13.92 \\
\hline
\end{tabular}

Table S2. Flexibility $(f)$, Gibbs free energy $\Delta G(\mathrm{~kJ} / \mathrm{mol})$ and the threshold $(K)$ of the PDMS-UPy and PDMS-BE at $40^{\circ} \mathrm{C}$.

\begin{tabular}{llll}
\hline Sample & Flexibility & \multicolumn{1}{c}{$\boldsymbol{G}$} & $\boldsymbol{K}$ \\
& $(f)$ & $(\mathbf{k J} / \mathbf{m o l})$ & \\
\hline PDMS-UPy & 0.716 & -15.29 & 0.642 \\
PDMS-BE & 0.692 & -14.56 & 0.643 \\
\hline
\end{tabular}


Table S3. The crosslink density and $T_{\mathrm{g}}$ of samples with different molar ratios of UPy and BE.

\begin{tabular}{|c|c|c|c|c|c|}
\hline Sample & PDMS-UPy & BE-PDMS $_{1: 15-U P y}$ & BE-PDMS $_{1: 3-U P y}$ & BE-PDMS $_{1: 2}$-UPy & PDMS-BE \\
\hline $\begin{array}{c}\text { crosslink density } \\
\left(\mathbf{m o l} / \mathrm{cm}^{-3}\right) \\
\end{array}$ & $2.74 \times 10^{-4}$ & $2.82 \times 10^{-4}$ & $3.02 \times 10^{-4}$ & $3.23 \times 10^{-4}$ & $3.48 \times 10^{-4}$ \\
\hline$T_{\mathrm{g}}\left({ }^{\circ} \mathbf{C}\right)$ & -70 & -17 & -13 & 37 & 62 \\
\hline
\end{tabular}

Table S4. Self-healing performance of BE-PDMS $1: 3$-UPy at different temperatures.

\begin{tabular}{|c|c|c|c|}
\hline Temperature $\left(T,{ }^{\circ} \mathrm{C}\right)$ & Time (h) & $\sigma(\mathrm{MPa})$ & $\eta_{\sigma}(\%)$ \\
\hline \multirow{6}{*}{-10} & 1 & $0.22 \pm 0.05$ & $2.12 \pm 0.14$ \\
\hline & 6 & $0.79 \pm 0.10$ & $10.33 \pm 0.07$ \\
\hline & 10 & $1.96 \pm 0.52$ & $27.38 \pm 0.21$ \\
\hline & 20 & $2.76 \pm 0.24$ & $38.73 \pm 0.17$ \\
\hline & 40 & $3.86 \pm 0.08$ & $53.62 \pm 0.15$ \\
\hline & 80 & $5.12 \pm 0.53$ & $73.14 \pm 0.11$ \\
\hline \multirow{6}{*}{10} & 1 & $0.92 \pm 0.43$ & $12.81 \pm 2.01$ \\
\hline & 5 & $3.17 \pm 0.34$ & $42.67 \pm 2.14$ \\
\hline & 10 & $4.35 \pm 0.56$ & $60.19 \pm 2.22$ \\
\hline & 20 & $5.48 \pm 0.20$ & $75.24 \pm 1.56$ \\
\hline & 40 & $5.99 \pm 0.17$ & $82.77 \pm 1.88$ \\
\hline & 50 & $6.51 \pm 0.29$ & $90.43 \pm 0.79$ \\
\hline \multirow{5}{*}{20} & 1 & $1.22 \pm 0.22$ & $16.86 \pm 0.92$ \\
\hline & 5 & $3.78 \pm 0.44$ & $52.19 \pm 2.32$ \\
\hline & 10 & $5.10 \pm 0.68$ & $70.24 \pm 1.27$ \\
\hline & 20 & $5.77 \pm 0.29$ & $83.73 \pm 2.87$ \\
\hline & 30 & $6.85 \pm 0.17$ & $94.86 \pm 0.55$ \\
\hline \multirow{6}{*}{30} & 0.5 & $1.15 \pm 0.26$ & $15.86 \pm 0.97$ \\
\hline & 1 & $2.01 \pm 0.61$ & $27.67 \pm 3.14$ \\
\hline & 2 & $2.92 \pm 0.05$ & $40.19 \pm 2.14$ \\
\hline & 5 & $4.46 \pm 0.03$ & $61.24 \pm 1.49$ \\
\hline & 10 & $5.88 \pm 0.24$ & $82.73 \pm 0.23$ \\
\hline & 15 & $7.06 \pm 0.21$ & $96.86 \pm 0.17$ \\
\hline \multirow{5}{*}{40} & 0.5 & $1.26 \pm 0.13$ & $16.27 \pm 0.63$ \\
\hline & 1 & $2.69 \pm 1.00$ & $35.35 \pm 0.37$ \\
\hline & 2 & $3.80 \pm 0.19$ & $49.01 \pm 0.22$ \\
\hline & 4 & $5.22 \pm 0.23$ & $79.04 \pm 0.24$ \\
\hline & 6 & $7.33 \pm 0.41$ & $97.69 \pm 0.33$ \\
\hline
\end{tabular}


Table S5. The $\Delta \eta_{\sigma}$ of BE-PDMS, PDMS-UPy and BE-PDMS $1: 3-\mathrm{UPy}$ in $\eta_{\sigma}$ at $40^{\circ} \mathrm{C}$.

\begin{tabular}{|c|c|c|c|}
\hline Samples & $\eta_{\sigma-1}(1 \mathrm{~h}, \%)$ & $\eta_{\sigma-6}(6 \mathrm{~h}, \%)$ & $\Delta \eta_{\sigma}=\eta_{\sigma-6}-\eta_{\sigma-1}(\%)$ \\
\hline BE-PDMS & $16.92 \pm 0.25$ & $43.91 \pm 0.19$ & 26.99 \\
\hline PDMS-UPy & $42.46 \pm 0.32$ & $95.12 \pm 0.28$ & 52.66 \\
\hline BE-PDMS $_{1: 3}$-UPy & $35.35 \pm 0.37$ & $97.69 \pm 0.33$ & $62.34 \%$ \\
\hline
\end{tabular}

Table S6. Summary of the self-healing polymer materials reported in literatures (contain PDMS).

\begin{tabular}{lllllll}
\hline Sample & $\boldsymbol{E}(\mathbf{M P a})$ & $\boldsymbol{\sigma}(\mathbf{M P a})$ & $\boldsymbol{T}\left({ }^{\mathbf{0}} \mathbf{C}\right)$ & Time $(\mathbf{h})$ & $\boldsymbol{\eta}_{\boldsymbol{\sigma}}(\mathbf{\%})$ & Ref. \\
\hline Py-PDMS-Co-1 & - & 0.35 & 25 & 24 & 71 & $\mathrm{~S} 3$ \\
Boroxine-PDMS & $182 \pm 15.8$ & $9.64 \pm 0.28$ & 70 & 12 & 95 & $\mathrm{~S} 4$ \\
PDMS-1 & $2.34 \pm 0.22$ & $1.66 \pm 0.35$ & 25 & 4 & 95 & $\mathrm{~S} 5$ \\
U-PDMS0.9K-Es & $0.23 \pm 0.07$ & $1.1 \pm 0.18$ & 40 & 2 & 100 & $\mathrm{~S} 6$ \\
PDMS-MPU $0.4-\mathrm{IU}_{0.6}$ & $0.62 \pm 0.06$ & 1.5 & 25 & 48 & 72 & $\mathrm{~S} 7$ \\
PDMS (A4) & - & 1.75 & 100 & 2 & 85 & $\mathrm{~S} 8$ \\
$(\mathrm{UP})_{3} \mathrm{~T}$ & $47.39 \pm 1.03$ & $5.40 \pm 0.23$ & 40 & 12 & 77.5 & $\mathrm{~S} 9$ \\
Zn (Hbimcp)2-PDMS & $43.68 \pm 3.27$ & 3.22 & 25 & 24 & $98.9 \pm 1.9$ & $\mathrm{~S} 10$ \\
BE-PDMS $1: 3-\mathrm{UPy}$ & $130.46 \pm 10$ & $7.33 \pm 0.41$ & 40 & 6 & $97.69 \pm 0.33 \%$ & This work \\
\hline
\end{tabular}

Table S7. Summary of the graphene/polymers composites materials reported in literatures.

\begin{tabular}{lllllll}
\hline Sample & $\boldsymbol{E}(\mathbf{M P a})$ & $\boldsymbol{\sigma}(\mathbf{M P a})$ & $\boldsymbol{T}\left({ }^{\mathbf{0}} \mathbf{C}\right)$ & Time $(\mathbf{h})$ & $\boldsymbol{\eta}_{\boldsymbol{\sigma}}(\mathbf{\%})$ & Ref. \\
\hline graphene/PDMS-urea & 100 & 17.5 & 50 & 0.8 & 95 & $\mathrm{~S} 11$ \\
SHPU/grapheme & - & 4 & 30 & 3 & 39 & $\mathrm{~S} 12$ \\
NR/Graphene- 2 & $0.22 \pm 0.01$ & $4.59 \pm 0.08$ & 70 & 7 & 70 & $\mathrm{~S} 13$ \\
PANDA/Gr-0.6 & $520 \pm 36$ & $22.3 \pm 1.9$ & 75 & 24 & $39 \pm 4$ & $\mathrm{~S} 14$ \\
PU-EDM/rmGO-1 & $104 \pm 17.46$ & $31.16 \pm 3.30$ & 65 & 48 & 62 & $\mathrm{~S} 15$ \\
PU/MG050 & 18.69 & 7.10 & 30 & 3 & 39.63 & $\mathrm{~S} 16$ \\
BE-PDMS $1: 3-U P y / G A U$ & $245.65 \pm 5$ & $39.63 \pm 3.73$ & 40 & 6 & $78.83 \pm 2.40(1)$ & This work \\
& & & & & $70.89 \pm 2(10)$ & \\
\hline
\end{tabular}

Table S8. The material parameters in the FES analysis system.

\begin{tabular}{lccc}
\hline Material & $\begin{array}{c}\text { Density } \\
\left(\mathbf{k g} / \mathbf{m}^{\mathbf{3}}\right)\end{array}$ & $\begin{array}{c}\text { Specific heat capacity } \\
\left(\mathbf{J} / \mathbf{~ k g} \cdot{ }^{\circ} \mathbf{C}\right)\end{array}$ & $\begin{array}{c}\text { Thermal conductivity } \\
(\boldsymbol{k}, \mathbf{W} / \mathbf{m ~ K})\end{array}$ \\
\hline BE-PDMS $1: 3$-UPy & 130 & 800 & 0.15 \\
rGO & 350 & 700 & 500 \\
Air & 0.00129 & 1003 & 0.023 \\
\hline
\end{tabular}


Table S9. The structural parameters in the FES.

\begin{tabular}{lccc}
\hline Models & Length $(\boldsymbol{\mu m})$ & Width $(\boldsymbol{\mu m})$ & Height $(\boldsymbol{\mu m})$ \\
\hline Composite & 30 & 30 & 35 \\
\hline
\end{tabular}

\section{REFERENCES}

S1. Yu, H.; Zhang, B.; Bulin, C.; Li, R.; Xing, R. High-Efficient Synthesis of Graphene Oxide Based on Improved Hummers Method. Sci. Rep. 2016, 6, 36143.

S2. Kim, C.; Ejima, H.; Yoshie, N. Polymers with autonomous self-healing ability and remarkable reprocessability under ambient humidity conditions. J. Mater. Chem. A 2018, 6, 19643-19652.

S3. Liu, L.; Liang, S.; Huang, Y.; Hu, C.; Yang, J. A Stretchable Polysiloxane Elastomer with SelfHealing Capacity at Room Temperature and Solvatochromic Properties. Chem. Commun. 2017, 89, 12088-12091.

S4. Lai, J. C.; Mei, J. F.; Jia, X. Y.; Li, C. H.; You, X. Z.; Bao, Z. A Stiff and Healable Polymer Based on Dynamic-Covalent Boroxine Bonds. Adv. Mater. 2016, 28, 8277-8282.

S5. Lv, C.; Zhao, K; Zheng, J. A Highly Stretchable Self-Healing Poly (Dimethylsiloxane) Elastomer with Reprocessability and Degradability. Macromol. Rapid Commun. 2018, 8, 1700686.

S5. Lv, C.; Zhao, K.; Zheng, J. A Highly Stretchable Self-Healing Poly (Dimethylsiloxane) Elastomer with Reprocessability and Degradability. Macromol. Rapid Commun. 2016, 8, 1700686.

S6. Cao, P. F.; Li, B.; Hong, T.; Townsend, J.; Qiang, Z.; Xing, K. Y.; Vogiatzis, K.; Wang, Y. Y.; Mays, J.; Sokolov, A.; Saito, T. Superstretchable, Self-Healing Polymeric Elastomers with Tunable Properties. Adv. Funct. Mater. 2018, 22, 1800741.

S7. Kang, J.; Son, D.; Wang, G.; Liu, Y. X.; Lopez, J.; Kim, Y.; Oh, J. Y.; Katsumata, T.; Mun, J.; Lee, Y.; Jin, L.; Bao, Z. Tough and Water-Insensitive Self-Healing Elastomer for Robust Electronic Skin. Adv. Mater. 2018, 13, 1706846.

S8. Zhang, D. D.; Ruan, Y. B.; Zhang, B. Q.; Qiao, X.; Deng, G. H.; Chen, Y. M.; Liu, C. Y. A SelfHealing PDMS Elastomer Based on Acylhydrazone Groups and The Role of Hydrogen Bonds. 
Polymer 2017, 120, 189-196.

S9. Liu, M. J.; Liu, P.; Lu, G.; Xu, Z. T.; Yao, X. Multiphase-Assembly of Siloxane Oligomers with Improved Mechanical Strength and Water-Enhanced Healing. Angew. Chem. Int. Ed. 2018, 35, $11412-11416$.

S10 Lai, J. C.; Jia, X. Y.; Wang, D. P.; Deng, Y. B.; Zheng, P.; Li, C. H.; Zuo, J. L.; Bao, Z. N. Thermodynamically Stable Whilst Kinetically Labile Coordination Bonds Lead to Strong and Tough Self-Healing Polymers. Nat. Commun. 2019, 10, 1164.

S11 Fang, M.; Li, D.; Lin, H. C.; Luo, C. H.; Qi, R. J.; Peng, H. Flexible and Recyclable Conductive Composite Based on Few-Layered Graphene with Excellent Self-Healing Capability. Eur. Poly. $J .2018,108,536-541$.

S12 Fang, M.; Li, D.; Lin, H. C.; Luo, C. H.; Qi, R. J.; Peng, H. Flexible and Recyclable Conductive Composite Based on Few-Layered Graphene with Excellent Self-Healing Capability. Eur. Poly. J. 2018, 108, 536-541.

S13 Hernandez, M.; Bernal, M. M.; Garcia, S. J. Effect Of Graphene Content On The Restoration of Mechanical, Electrical and Thermal Functionalities of A Self-Healing Natural Rubber. Smart Mater. Struct. 2017, 8, 085010.

S14 Cai, C. T.; Zhang, Y.; Li, M; Chen, Y.; Zhang, R. C.; Wang, X. L.; Wu, Q.; Chen, T. H.; Sun, P. C. Multiple-Responsive Shape Memory Polyacrylonitrile/Graphene Nanocomposites with Rapid Self-Healing and Recycling Properties. RSC Adv. 2018, 3, 1225-1231.

S15 Lin, C. H.; Sheng, D. K.; Liu, X. D.; Xu, S. B.; Ji, F. C.; Li, D.; Zhou, Y.; Yang, Y., M. NIR Induced Self-Healing Electrical Conductivity Polyurethane/Graphene Nanocomposites Based on Diels? Alder Reaction. Polymer 2018, 140, 150-157.

S16 Kim, J. T.; Kim, B. K.; Kim, E. Y.; Kwon, S. H.; Jeong, H. M. Synthesis and Properties of Near IR Induced Self-Healable Polyurethane/Graphene Nanocomposites. Eur. Poly. J. 2013, 12, 38893896. 